\title{
Personhood Communication with Persons with Dementia: Concept Analysis
}

\author{
Kim, Jiyeon ${ }^{1} \cdot$ Song, Jun-Ah ${ }^{2}$ \\ ${ }^{1}$ Graduate Student, College of Nursing, Korea University, Seoul \\ ${ }^{2}$ Professor, College of Nursing · BK21 FOUR R\&E Center for Learning Health Systems, Korea University, Seoul, Korea
}

\begin{abstract}
Purpose: This paper aimed to clarify the meaning of personhood communication with persons with dementia, by identifying its attributes. Methods: Walker and Avant's concept analysis method was employed. A literature review was performed using salient medical and health databases such as PubMed, Embase, and CINAHL between 1988 to June 2020. The literature review employed keywords such as "personhood", "communication", and "dementia". Results: Personhood communication with persons with dementia is defined as providing social interaction based on their residual capacities, with adjustments being made in light of their remaining communication abilities, attentiveness to their emotions and respect for their individuality being shown, and decision-making rights being maintained. Conclusion: At the core of personhood communication is respect for persons with dementia and the goal of enabling them to be valid members of society. Further research is needed on the development of educational programs that impart the attributes of personhood communication with persons with dementia.
\end{abstract}

Key Words: Dementia; Communication; Personhood; Qualitative research

\section{INTRODUCTION}

The global population of persons with dementia (PWD) is growing. Currently there is no way to completely cure dementia, so many countries are interested in establishing policies that focus on the quality of life of PWD. The World Health Organization (WHO) established a specific policy to improve PWD's quality of life by promoting their needs and treating them as dignified beings [1]. The basic tenet of this policy is Person-Centered Care (PCC), which revolves around the concept of personhood. Personhood is the constitutive element of human beings, and it entails the acknowledgement of the status of others on the basis of respect and trust [2,3]. Personhood is maintained by interpersonal interaction [3], and communication is an essential element [3-5]. Personhood is sustained by understanding and responding to the individual in the interactive process of verbal and non-verbal communication, and it should be pursued until the end stage of dementia. The practice of personhood communication in dementia care is being widely emphasized $[3,4]$. Although the terms 'personhood communication' and 'person-centered communication' are used interchangeably [6], the concept has not yet been clearly defined.

PWD have difficulty communicating and face challenges in expressing their thoughts and emotions. Caregivers have difficulty understanding PWD, and this leads to stress and burnout $[7,8]$. It has been reported that caregivers' lack of communication skills in relation to PWD is related to their increased stress levels [9]. Therefore, many studies have focused on how to improve caregivers' communication abilities in this area. A recent systematic review study reported that communication interventions such as using memory books, providing a comforting environment, being aware of negative communication and reading emotions were effective [9]. And a previous study showed that education aimed at improving caregivers' knowledge and skills reduces communication difficulties

\footnotetext{
Corresponding author: Song, Jun-Ah https://orcid.org/0000-0002-2736-4037

College of Nursing, Korea University, 145 Anam-ro, Seongbuk-gu, Seoul 02841, Korea.

Tel: +82-2-3290-4921, Fax: +82-2-927-4676, E-mail: jasong@korea.ac.kr

Received: Aug 19, 2021 / Revised: Oct 26, 2021 / Accepted: Nov 19, 2021

This is an open access article distributed under the terms of the Creative Commons Attribution Non-Commercial License (http://creativecommons.org/licenses/ by-nc/3.0), which permits unrestricted non-commercial use, distribution, and reproduction in any medium, provided the original work is properly cited.
} 
and improves the quality of life of both caregivers and PWD [7]. In recent systematic review studies, personhood communication has been demonstrated to be a useful way to communicate effectively with PWD [5,7]. Another empirical study of PWD has shown that maintaining their sense of personhood is an important factor in improving their quality of life [10]. In light of this work, it is clear that communication and a focus on personhood are important elements in maintaining PWD's quality of life.

As such, the importance and necessity of personhood communication is now emphasized, but there is still a gap between this recognition and the practice of PWD care [11]. Researchers have proposed that the reasons for the low uptake of personhood practices are the ambiguity of the concept and the lack of understanding of its social implications [11,12]. This suggests the need for research to clarify the definition and the properties of the concept of personhood communication.

This study aims to analyze the concept of personhood communication with PWD, and how it can be beneficial to PWD, caregivers, and healthcare providers. The results of this study provide basic information which can be helpful in formulating guidelines for establishing practical strategies of personhood communication with PWD.

\section{Determining the Aims of the Analysis}

The concept of personhood communication with PWD has been insufficiently studied, and hence lacks a clear definition. This paper refines the meaning of personhood communication with PWD by identifying its critical attributes and practical uses.

\section{METHODS}

This study employs the Walker and Avant's (2011) model, which is a systematic approach to the elucidation of ambiguous or vague ideas that are frequently drawn upon in nursing [13]. This rigorous model is the most broadly applied in the literature, and all of its inherent and explicit applications are considered. It is assumed that the concept may change slightly as times change, but its essence is not likely to evolve. This analysis is comprised of an iterative process consisting of six steps: (a) choosing the concept to be studied, (b) deciding the aim of the study, (c) identifying the uses of the concept, (d) clarifying its defining attributes, (e) giving examples to illuminate it, and (f) detecting its antecedents, consequences, and clear empirical referents.

\section{Literature Review}

A literature review was performed using salient medical and health databases, but it was not restricted to the medical or nursing fields. This broad review was conducted in order to understand the true nature of the concept of personhood communication, as advanced by Walker and Avant (2011)[13]. The databases used were PubMed, EMBASE, and CINAHL. These are comprehensive databases containing data up to June 2020. The keywords used were: "cognitive", "impairment”, "dementia”, "Alzheimer", "personhood”, "person-centered," "client-centered", "verbal", "non-verbal", "interaction" and "communication". A total of 3,434 paper abstracts and 11 full papers were searched, resulting in a total of 3,445 papers searched. By removing duplicates, book reviews, and full papers that were unavailable, 469 studies were excluded. After screening titles and abstracts, 2,801 texts were further excluded because they were unrelated to personhood communication. During the evaluation of 175 full papers remained, 128 articles were excluded because they were not germane to identify the essential meaning of the concept. Eventually, 47 articles were included in the final review for the concept analysis (Figure 1).

\section{RESULTS}

\section{Identifying the Use of the Concept}

Personhood is defined as "a standing or status that is bestowed upon one human being, by others, in the context of relationship and social being" [3]. It also means the maintenance of their subjectivity in their social interactions [14]. Buron [15] presented personhood as comprised of three levels, similar to Maslow's hierarchy of needs [16], and in this model, the higher the level, the harder it is to sustain. The first level is biological personhood. This is the necessary physiological element of life, and at its center is the perceptive capacity to feel. In other words, it refers to the ability to feel joy and pain, as well as the basis of the need for food, safety, hygiene, clothing, and healthcare. The second level is individual personhood, which refers to factors including a person's personality and their roles as they go through life, their values, and spiritual leanings. The third level is sociological personhood, which is comprised of the perception of a person's status in relation to others in their interactions in the social context, and in the context of the care and treatment of persons. Buron argued that verbal and non-verbal communication is essential to maintaining 


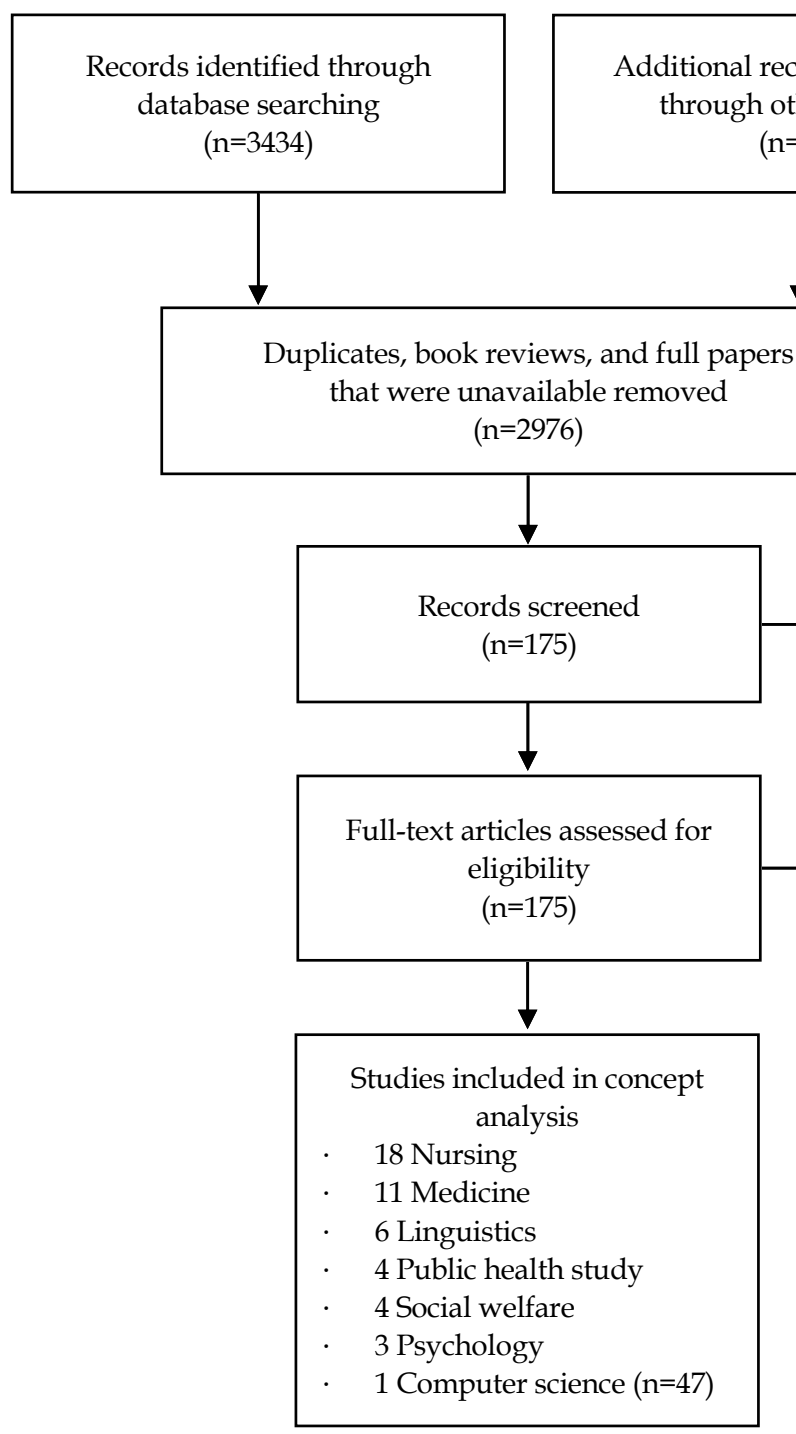

Additional records identified through other sources $(\mathrm{n}=11)$

Figure 1. Data search and selection process.

three-level personhood [15].

Personhood communication enables the maintenance of individual autonomy [17]. Its aims are to recognize the needs of PWD, respect individual preferences and needs, participate in meaningful communication, and acknowledge and empathize their actions and thoughts [18]. It is also focused on the environment of PWD, and on understanding their behavior with empathy, helping them maintain their sense of self, and reducing their anxiety using verbal and non-verbal communication methods [12].

\section{Defining Attributes}

Attributes are characteristics associated with a concept that define it. This concept analysis identified five defining attributes of personhood communication from the included articles: 1) providing social interaction on the basis of residual capacities of PWD, 2) adjusting to PWD remaining communication abilities, 3) reading PWD emotions, 4) respecting PWD individuality, and 5) maintaining PWD decision-making rights. Table 1 presents the defining attributes and sub-attributes and lists studies supporting each of the attributes.

\section{1) Providing social interaction on the basis of residual ca- pacities of PWD}

Through personhood communication, PWD are perceived to have communication abilities. By participating in communication, they can play social roles and be recognized as social beings. The recognition of the specific rights and obligations of PWD in dialogue allows them to play a social role [19]. By focusing on PWD's remaining communication capacities and providing communication opportunities to them, PWD are helped in maintaining 
Table 1. Defining Attributes of Personhood Communication with Persons with Dementia in Literature

\begin{tabular}{|c|c|c|}
\hline Attribute & Sub-attribute & Reference number \\
\hline $\begin{array}{l}\text { Providing social interaction } \\
\text { on the basis of residual } \\
\text { capacities of PWD }\end{array}$ & $\begin{array}{l}\text { Acknowledging PWD have ability to communicate } \\
\text { Encouraging participation in communication by giving } \\
\text { PWD an opportunity to speak }\end{array}$ & $\begin{array}{l}20,27,39,45,62 \\
3,19,20,21,22,38,50,63,64 \\
65,66\end{array}$ \\
\hline \multirow[t]{2}{*}{$\begin{array}{l}\text { Adjusting to remaining PWD } \\
\text { communication abilities }\end{array}$} & $\begin{array}{l}\text { Using of communication skills tailored to the } \\
\text { communication ability and cognitive level of PWD }\end{array}$ & $\begin{array}{l}21,22,26,27,30,34,42,43 \\
52,66,67\end{array}$ \\
\hline & $\begin{array}{l}\text { Reducing communication gap by aligning the center of } \\
\text { communication with PWD }\end{array}$ & $21,25,26,43,53,68$ \\
\hline \multirow[t]{2}{*}{ Reading PWD emotions } & - Acknowledging PWD have feelings & $\begin{array}{l}3,22,31,32,38,39,44,47,51 \\
54,69,70\end{array}$ \\
\hline & - Empathizing & $25,33,34,42,70,71$ \\
\hline \multirow[t]{3}{*}{$\begin{array}{l}\text { Respecting PWD } \\
\text { individuality }\end{array}$} & - Considering individual uniqueness & $\begin{array}{l}19,21,26,30,31,32,34,36,38 \\
44,45,46,47,49,50,51,52,53 \\
56,62,64,68,72,73,74\end{array}$ \\
\hline & - Showing respectful attitude & $\begin{array}{l}21,22,31,39,41,42,44,51 \\
52,63,64,67,68,75,76\end{array}$ \\
\hline & - Maintaining positive relationship & $\begin{array}{l}20,22,26,37,39,42,43,52 \\
63,75\end{array}$ \\
\hline \multirow{3}{*}{$\begin{array}{l}\text { Maintaining PWD } \\
\text { decision-making rights }\end{array}$} & - Acknowledging PWD have right to decide & $37,46,51,53$ \\
\hline & - Acknowledging PWD able to act independently & $22,30,39,42,47$ \\
\hline & - Providing opportunity to make choice & $22,39,44,45,46,47,55,72$ \\
\hline
\end{tabular}

PWD=Persons with dementia.

their communication skills [20,21].

The communication-enhancing model proposes that physical and environmental adjustments are needed to enable PWD to participate in communication [5]. PWD are more sensitive to stimuli, so they can focus more on communication on the basis of considered environmental adjustments [22]. For example, hearing loss accelerates brain atrophy, which requires noise management to enable productive conversation with PWD [23].

\section{2) Adjusting to remaining PWD communication abilities}

Impaired cognitive function causes reduced information processing on the part of PWD. Therefore, when multiple reasoning processes are required in a given situation, PWD have difficulties in interpretation and understanding. For example, in the query "Could you tell me what happened to give you headaches?" there are three main verbs (tell, happened, and give), making it challenging for PWD to understand. Short utterances of four to six words are best understood by PWD [24].

In responding to what PWD has said, the listener uses an indirect or direct repair strategy. In the indirect strategy, the listener provides additional descriptive informa- tion through paraphrasing PWD's intended purpose, while in the direct strategy, the listener points out PWD's errors (i.e., word-finding difficulties, misunderstanding), interjects corrective feedback, and infringes on the personhood of PWD by punishing their verbal behavior [25]. In conversation with PWD, if the other individual explains verbally while also illustrating the explanation through body language, the PWD can understand well [26]. PWD can express themselves verbally in the early and middle stages of dementia, so it is useful to communicate with them in words at those points [6]. In the end stage of dementia, verbal activity completely disappears and communication can be sustained in non-verbal ways [27].

Both the See-Saw model [28] and Communication Accommodation Theory [29] argue that conversations with PWD should have a focus on filling gaps in their language abilities. These gaps can be narrowed by adjusting speaking speed, as well as by matching the words and gestures used with the capacities of PWD [28,29]. This helps to enhance PWD's sense of their own personhood in communication by enabling them to express what they think [30]. 


\section{3) Reading PWD emotions}

Personhood communication helps caregivers recognize that PWD have rich emotions and acknowledge and empathize their current state of mind. For example, validation therapy consists of the identification of the emotions and needs of PWD [22,31] and is a strategy to bolster the personhood of PWD [3]. This form of therapy recognizes PWD's current perceptions and emotions even if PWD have hallucinations [32]. Empathy allows the understanding of the emotions of PWD [33] and fosters respect for them [34]. Caregivers put PWD at ease by acknowledging their fear when PWD are confused or struggling. It has been found that emotional responses still exist in people with amnesia after their memories have disappeared [35]. This proposition is supported by the symbolic interactionist view that the self is concealed rather than lost as dementia progresses [32].

\section{4) Respecting PWD individuality}

Personhood communication considers the personalities, preferences, occupations, and lifestyles of PWD, and displays respect for them through the attitude it entails. In addition, it displays a positive attitude toward PWD by accommodating their perspectives even when they are different from what it is assumed they are.

Wilson, Cochrane, Mihailidis, \& Small [36] proposed that communication should include multifaceted aspects of PWD, including their life history. Reminding PWD of information related to them enhances their awareness of their place in society [37] and increases their sense of presence $[37,38]$. In this way, the sense of identity of PWD can be maintained [38].

Elderspeak is called "baby-talk" because it does not differ from the pattern used in addressing babies [39]. PWD see elderspeak as treating them like children and as a way of ignoring them, and they display lack of self-esteem and dissatisfaction in conversations in which it is used [40]. Ultimately, elderspeak threatens the positive self-concept of PWD, and must be avoided [41].

PWD may perceive things differently but they are not necessarily wrong, but negative expressions may make them feel that they are not an acceptable presence [42]. Conversely, when PWD receive affirmation, their sense of self can be better maintained [37]. Positive gestures, such as eye contact and smiling, and kind behavior, allow PWD to feel relaxed and loved, and promote good interactions [22,43].

\section{5) Maintaining PWD decision-making rights}

Personhood communication provides an opportunity for PWD to make choices by acknowledging that they have the right to make decisions for themselves and can act independently. The Person-Centered Behavior Inventory (PCBI) measures personhood by encouraging caregivers to provide A or B options to PWD when communicating with them [44]. The presence of options allows PWD to express their opinion, and as a result they are able to feel that they are not being controlled by others, and that they have ownership over their own lives $[45,46]$.

\section{Model and Additional Cases}

A model case is a paradigmatic instance of a concept's application containing all its attributes, a contrary case represents an instance of what the concept is not, while a borderline case contains some but not all of its defining attributes [13].

\section{1) Model case}

Gil Woo is an 82-year-old male with middle stage dementia. He likes to be called by his name. He is pacing around the nurses' station looking for something.

Nurse: Gil Woo, what are you looking for? You look like it is urgent.

Gil Woo:(He does not even look at the nurse's face.) No.

Even though the nurse is talking, Gil Woo does not listen to her and remains focused on what he is looking for. The nurse taps Gil Woo's arm and tells him that she will help him. Gil Woo speaks confusingly, but the words "blue and square" can be clearly understood. Making the shape of a square notebook with her hands, she asks Gil Woo if this is what he is looking for.

Gil Woo: Oh!

She asks Gil Woo if he would like to go with her to find it. In this case, the nurse tapped Gil Woo's arm to encourage him to participate in the conversation, and when Gil Woo's words were confusing, she restated them in order to confirm his meaning. In addition, the nurse read the emotions in his facial expressions, and she said his name in a way Gil Woo liked. She asked him if he would like to go and find the notebook with her, and gave him decision-making rights.

\section{2) Contrary case}

Jung Sook is an 86-year-old female with middle stage dementia. She has a habit of looking for food even if it has not been long since she last ate. The nurse finds her in the kitchen, as she was absent from the cognitive therapy class. 
Nurse: Madam, why are you here?

Jung Sook: Have $\cdots$ to eat $\cdots$ (She is trying to say something.)

Nurse:(Speaking before Jung Sook finishes speaking, at a fast pace.) We ate in the restaurant. Let's stop bothering with that and attend the cognitive therapy class.

Jung Sook:(Lowering her head, her face clouded over. Mumbling incomprehensibly.) I $\cdots$ don't $\cdots$ like $\cdots$ that $\cdots$

Nurse: What are you saying? I cannot understand you because you are muttering.(While taking Jung Sook's hand.) Let's go to the class.

In this case, the nurse spoke before Jung Sook's words were finished, taking away the opportunity for her to communicate. The nurse spoke at a rapid speed and in long sentences without considering Jung Sook's communication ability. She didn't take Jung Sook's feelings into account and was coercive. She did not accept Jung Sook's refusal to attend class and did not give her decision-making rights.

\section{3) Borderline case}

Mi Kyoung is an 87-year-old female with early stage dementia. She is sitting on the couch in the living room after a bath.

Daughter: Mom, you used to love hiking.

Mi Kyoung: Uh-huh. I thought... ah... ah...

Daughter: Are you talking about Achasan Mountain?

Mi Kyoung nods her head and tries to continue the conversation. Her daughter is aware of Mi Kyoung's attempt at talking, but she quickly continues to talk before Mi Kyoung speaks.

(After a while) Mi Kyoung points toward the bread on the living room table.

Daughter: Mom, are you hungry? Would you like some bread?

In this case, the daughter sustained Mi Kyoung's individuality by talking about her favorite climbing experience. She restated Mi Kyoung's words, confirming her meaning. She saw Mi Kyoung's hand pointing at the bread, sensed her hunger, and asked if she wanted to eat the bread, giving her decision-making rights. But she spoke before Mi Kyoung's words were finished, taking away her opportunity to communicate fully.

\section{Identify Antecedents and Consequences}

Antecedents are incidents or events that must occur prior to the application of a concept. Consequences are events that occur as an outcome of the concept [13].

\section{1) Antecedents}

To engage in personhood communication, it is necessary to see PWD as first and foremost human beings who are not simply sufferers of a disease, and to have broader knowledge of specific PWD's lives. The first involves recognizing PWD as members of society rather than simply as patients [47]. Considering PWD as distinct from or not wholly defined by their illness, which means not emphasizing incapacities due to dementia, allows them to act as members of society more fully [48].

By accessing information about PWD, caregivers can understand their world better and help them maintain their sense of personhood [49]. This involves acknowledging them as persons with thoughts, feelings, and personalities, which allows PWD to retain a sense of selfidentity [3].

\section{2) Consequences}

Some studies have found that considering and compensating for PWD communication-related difficulties could lessen their anxiety [50,51]. A positive and respectful attitude toward PWD influences the closeness of relationships between PWD and caregivers [31,51]. Acknowledging their perspective makes them feel comfortable and lowers their level of anxiety [25,49]. Making use of their personal information in conversation helps PWD feel that they enable them to retain consciousness of their self-identity [42,49,52]. Finally, providing options to PWD enables them to feel that they are in control of their lives $[19,31,38,45,47]$; moreover, it improves their quality of life [45,50,53-55](Figure 2).

\section{Empirical referents}

Empirical referents are defined as phenomena that demonstrate the practical reality of a concept [13]. Previous research has reported that communication including PWD personal information promotes their participation in communication and increases the amount of conversation they engage in [52]. Conversations that factor in the responses of PWD help to satisfy their needs and reduce their resistance behavior [44]. Conversely, communication which does not display respect for PWD leads to resistance behavior [56].

\section{DISCUSSION}

An emphasis on personhood is a practical philosophy in dementia care, and research aimed at furthering personhood in communication with PWD is being actively 


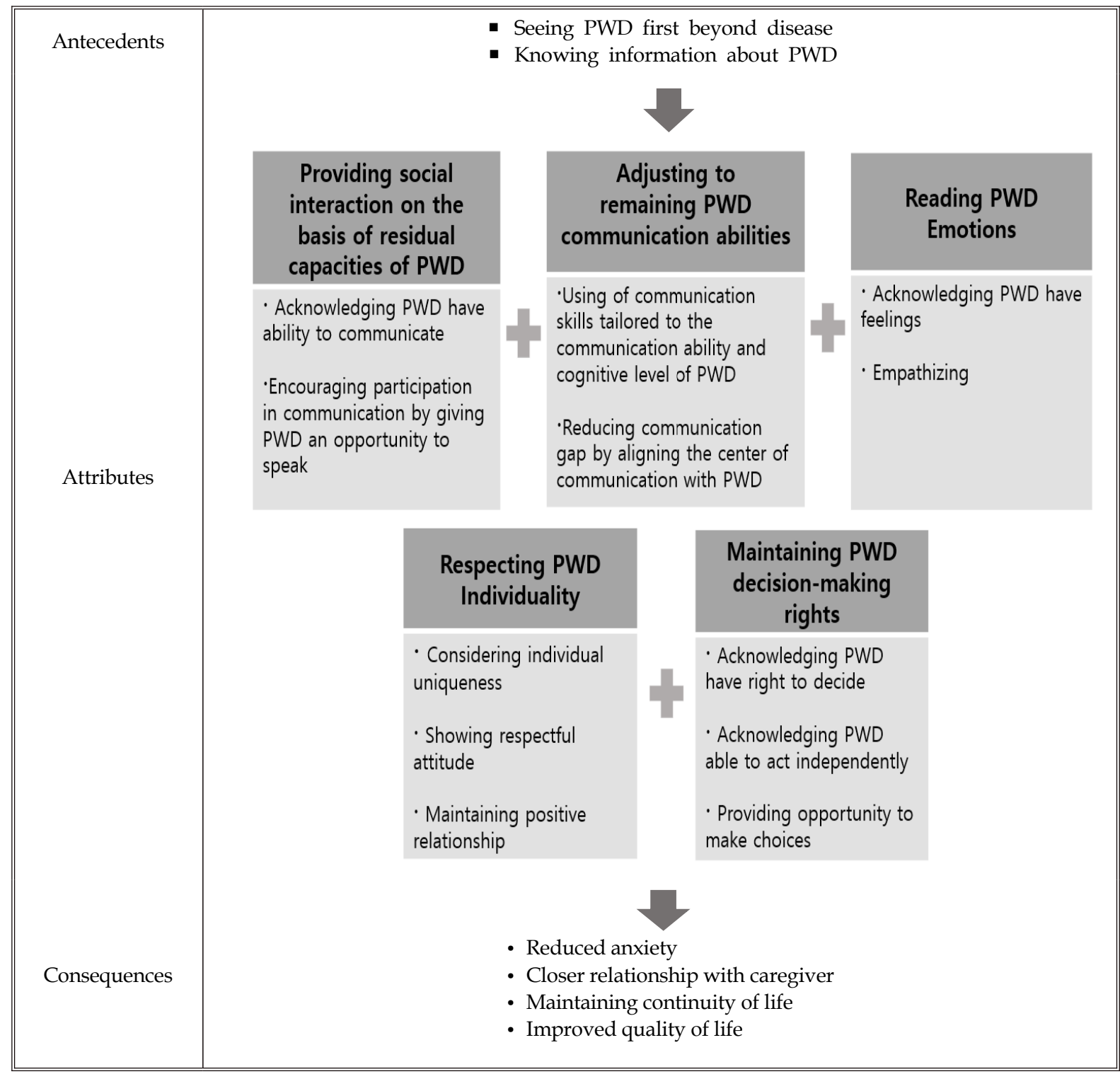

Note. PWD=persons with dementia.

Figure 2. Antecedents, attributes, and consequences of personhood communication with persons with dementia.

conducted. In this context, this study attempted to clarify the concept of personhood communication and to understand the contextual antecedents and consequences of this communication.

The first and second attributes of personhood communication are associated with a focus on the remaining communication abilities of PWD. The basis of Kitwood's model [57] is the Person-Centered Theory of Rogers [58]. In this theory, it is assumed that humans have the ability to achieve self-actualization, which is however obscured during their lives [58]. PWD have suffered from communication difficulties due to the stigma that has attached to communication with them, which has been viewed as un- reliable or disordered [59]. As a result of this stigma, PWD have been excluded from a full range of communication opportunities and have lost a sense of belonging as social beings [15]. This suggests that it is necessary to eliminate negative views surrounding dementia, and to see PWD as first and foremost full human beings who are not defined by their disease in order to achieve the goal of personhood communication.

The third attribute of personhood communication is more associated with non-verbal communication. In general, when opinions are expressed, this takes place at a level of only $7 \%$ through language, at $55 \%$ through body language, and at 38\% through tone of voice [60]. Regard- 
less of the level of cognitive functioning involved in communication, non-verbal communication accounts for a large part of it in general. As the ability to reason and think logically deteriorates, PWD express what they want to express with emotions in non-verbal ways $[15,60]$. These results suggest that in order to be sensitive to the emotions of PWD, caregivers need to pay attention to nonverbal communication. This form of communication varies among cultures and individuals, so prior understanding of PWD's background is necessary for personhood communication. Future studies on non-verbal communication which reflect the cultural differences among PWD are needed to help us understand the emotions of PWD.

The fourth attribute of personhood communication is related to the identity of PWD. When their distinctive characteristics are not recognized and they are treated as different to who they are, they feel existing dual role and sense discontinuity in their lives [10]. Conversely, PWD have been shown to engage in more interactions in individualized conversations and activities [8,59]. PWD living in care facilities complain more than others about a loss of identity $[10,59]$. This suggests that it is necessary to know the personal information of PWD who are admitted to care facilities and to incorporate it into each person's care plan. In this way, the identity of PWD can be maintained and thus their sense of personhood preserved.

Finally, the fifth attribute of personhood communication is associated with their decision-making. PWD say that decision-making is a means of expressing that they are independent and can manage their own lives [10]. A study that addressed whether PWD can give informed consent to participate in research reported that they could decide through the simplified decision-making process of choosing between options. These methods reduced their difficulty in understanding and interpreting by complementing their cognitive functions and enabling decision-making on their part [61], thereby supporting their autonomy. Ultimately, maintaining the autonomy of PWD leads to the preservation of their sense of personhood.

The findings of this study suggest that personhood communication can help meet the psychosocial needs of PWD. Through such communication, caregivers can act as advocates by reducing the difficulties of communication with PWD and maintain a supportive position by improving their relationships with them. In this way, caregivers can practice the nursing philosophy of enhancing human dignity. Moreover, the results of this study can constitute an essential foundation for personhood communication practice guidelines. Personhood communication should be implemented in clinical settings with the goal of enabling PWD to experience a positive relationship with their caregivers and to improve their quality of life. For example, nurses need to see PWD first beyond disease and know the PWD well to make them participate in the communication of daily living. In addition, nurses need to focus on adjusting the communication to PWD's remaining abilities, reading emotions, respecting individuality, and acknowledging that PWD still maintain decision-making rights. For this it is necessary to develop specific strategies for the successful implementation of personhood communication.

The limitations of this study are that it relies on limited empirical work on PWD, and it cannot be said that the subjective judgement of the researchers is completely absent in relation to the study's conception. There are differences in the communication ability of PWD according to their stage of dementia, but the personhood communication literatures have not examined this as a distinct issue. Therefore, additional research on personhood communication according to stages of dementia is needed. In addition, it would be of value to explore personhood communication from a two-way perspective that includes the experience of $\mathrm{PWD}$, by conducting observational studies using dyad samples.

\section{CONCLUSION}

Personhood communication ameliorates the difficulties of communication with PWD, and through it the human dignity of PWD can be valorized. In light of the global trend of pursuing policies which address the needs of PWD, interaction with PWD through personhood communication can be a useful way to help PWD and caregivers strengthen their relationships. There is a need for research on the effectiveness of personhood communication and the effectiveness of educational programs in this respect, in the context of the attributes of personhood communication identified in this study.

\section{CONFLICTS OF INTEREST}

The authors declared no conflict of interest.

\section{AUTHORSHIP}

Study conception and design - KJ and SJ-A; Data collection and processing - KJ; Analysis and interpretation of the data - KJ and SJ-A; Drafting and critical revision of the manuscript - KJ and SJ-A; Final Approval - SJ-A.

\section{ACKNOWLEDGEMENT}

This work was supported by the National Research Foundation 
of Korea (NRF) grant funded by the Korea government (MSIT) (2019R1A2C1086649).

\section{REFERENCES}

1. World Health Organization. Global action plan on the public health response to dementia 2017-2025. Geneva: World Health Organization; 2017. 44 p.

2. Dewing J. Participatory research: a method for process consent with persons who have dementia. Dementia. 2007;6(1):11-25. https://doi.org/10.1177/1471301207075625

3. Kitwood T. On being a person. In: Kitwood T, editor. Dementia reconsidered: the person comes first. 2nd ed. London: Open University Press; 2019. 176 p.

4. Alzheimer's society [Internet]. London: Alzheimer's society England; 2020 Mar 30 [updated 2020 Mar 30; cited 2021 May 9]. Available from:

https://www.alzheimers.org.uk/about-dementia/treatments /person-centred-care

5. Ennis L, Mansell W, McEvoy P, Tai S. A systematic scoping review and synthesis of dementia and communication theory. Dementia. 2019;18(6):2261-81. https://doi.org/10.1177/1471301217744069

6. Manthorpe J, Samsi K. Person-centered dementia care: current perspectives. Clinical Interventions in Aging. 2016;11:1733-40. https://doi.org/10.2147/CIA.S104618

7. Alsawy S, Mansell W, McEvoy P, Tai S. What is good communication for people living with dementia? a mixed- methods systematic review. International Psychogeriatrics. 2017;29(11): 1785-800. https://doi.org/10.1017/s1041610217001429

8. Downs M, Collins L. Person-centered communication in dementia care. Nurse Standard. 2015;30(11):37-41. https://doi.org/10.7748/ns.30.11.37.s45

9. Machiels M, Metzelthin SF, Hamers JP, Zwakhalen SM. Interventions to improve communication between people with dementia and nursing staff during daily nursing care: a systematic review. International Journal of Nursing Studies. 2017;66: 37-46. https://doi.org/10.1016/j.ijnurstu.2016.11.017

10. Nowell ZC, Thornton A, Simpson J. The subjective experience of personhood in dementia care settings. Dementia. 2013;12 (4):394-409. https://doi.org/10.1177/1471301211430648

11. Kim DE, Sakong H, Yoon JY. A delphi study for developing a person-centered dementia care online education program in long-term care facilities. Journal of Korean Academy of Community Health Nursing. 2019;30(3):295-306.

https://doi.org/10.12799/jkachn.2019.30.3.295

12. Young T, Manthorp C. Towards a code of practice for effective communication with people with dementing illnesses. Journal of Language and Social Psychology. 2009;28(2):174-89. https://doi.org/10.1177/0261927X08330611
13. Walker L, Avant K. Concept analysis. In: Walker L, Avant K, editors. Strategies for theory construction in nursing 6 th ed. New Jersey: Pearson Prentice Hall; 2011. p. 157-79.

14. Kitwood T, Bredin K. Towards a theory of dementia care: personhood and well-being. Ageing \& Society. 1992;12(3):269-87. https://doi.org/10.1017/s0144686x0000502x

15. Buron B. Levels of personhood: a model for dementia care. Geriatric Nursing. 2008;29(5):324-32.

https://doi.org/10.1016/j.gerinurse.2007.11.001

16. Maslow AH. A theory of human motivation. Psychological Review. 1943;50(4):370-96. https://doi.ogr/10.1037/h0054346

17. Elixhauser S. Setting the scene: communication, autonomy and personhood. In Elixhauser S, editor. Negotiating personal autonomy communication and personhood in East Greenland. Communication, autonomy, and personhood. London: Routledge; 2018. p. 13-25.

18. Savundranayagam MY, Ryan EB, Anas AP, Orange J. Communication and dementia: staff perceptions of conversational strategies. Clinical Gerontologist. 2007;31(2):47-63.

https://doi.org/10.1300/J018v31n02_04

19. Adams T, Gardiner P. Communication and interaction within dementia care triads: developing a theoryfor relationshipcentred care. Dementia. 2005;4(2):185-205.

https://doi.org/10.1177/1471301205051092

20. Young TJ, Manthorp C, Howells D, Tullo E. Developing a carer communication intervention to support personhood and quality of life in dementia. Ageing and Society. 2001;31(6):1003-25. https://doi.org/10.1017/S0144686X10001182

21. Wheeler NL, Oyebode JR. Dementia care 1: person centered approaches help to promote effective communication. Nursing Times. 2010;106(24):18-21.

22. Hammar LM, Emami A, Engström G, Götell E. Communicating through caregiver singing during morning care situations in dementia care. Scandinavian Journal of Caring Sciences. 2011; 25(1):160-8. https://doi.org/10.1111/j.1471-6712.2010.00806.x

23. Crosbie B, Ferguson M, Wong G, Walker DM, Vanhegan S, Dening T. Giving permission to care for people with dementia in residential homes: learning from a realist synthesis of hearing-related communication. BMC Medicine. 2019;17(1):1-16. https://doi.org/10.1186/s12916-019-1286-9

24. Weirather RR. Communication strategies to assist comprehension in dementia. Hawaii Medical Journal. 2010;69(3):72-4.

25. Savundranayagam MY, Sibalija J, Scotchmer E. Resident reactions to person-centered communication by long-term care staff. American Journal of Alzheimer's Disease \& Other Dementias ${ }^{\circledR}$. 2016;31(6):530-7. https://doi.org/10.1177/1533317515622291

26. Eggenberger E, Heimerl K, Bennett MI. Communication skills training in dementia care: a systematic review of effectiveness, 
training content, and didactic methods in different care settings. International Psychogeriatrics. 2013;25(3):345-58. https://doi.org/10.1017/s1041610212001664

27. Allwood R, Pilnick A, O'Brien R, Goldberg S, Harwood RH, Beeke S. Should I stay or should I go? how healthcare professionals close encounters with people with dementia in the acute hospital setting. Social Science \& Medicine. 2017;191: 212-25. https://doi.org/10.1016/j.socscimed.2017.09.014

28. Seifert L, Flaherty K, Trill K. Beyond person-centered dementia care: The see-saw model for day-to-day interactions. Activities Directors' Quarterly for Alzheimer's and Other Dementia Patients. 2013;14(2):15-31.

29. Harwood Giles, Ryan. Intergenerational communication: intergroup, accommodation, and family perspectives. In Angie Williams and Jake Harwood. editors. Handbook of communication and aging research. 2nd ed. New Jersey: Lawrence Erlbaum Associates; 2004. p. 120-1.

30. Grosch K, Medvene L, Wolcott H. Person-centered caregiving instruction for geriatric nursing assistant students: development and evaluation. Journal of Gerontological Nursing. 2008; 34(8):23-31. https://doi.org/10.3928/00989134-20080801-07

31. Savundranayagam MY, Moore-Nielsen K. Language-based communication strategies that support person-centered communication with persons with dementia. International Psychogeriatrics. 2015;27(10):1707-18.

https://doi.org/10.1017/s1041610215000903

32. Edvardsson D, Winblad B, Sandman PO. Person-centered care of people with severe Alzheimer's disease: current status and ways forward. The Lancet Neurology. 2008;7(4):362-7. https://doi.org/10.1016/s1474-4422(08)70063-2

33. McGovern J. Couple meaning-making and dementia: challenges to the deficit model. Journal of Gerontological Social Work. 2011;54(7):678-90. https://doi.org/10.1080/01634372.2011.593021

34. Williams CL, Newman D, Hammar LM. Preliminary study of a communication intervention for family caregivers and spouses with dementia. International Journal of Geriatric Psychiatry. 2018;33(2):e343-9. https://doi.org/10.1002/gps.4816

35. Feinstein JS, Duff MC, Tranel D. Sustained experience of emotion after loss of memory in patients with amnesia. Proceedings of the National Academy of Sciences. 2010;107(17):7674-9. https://doi.org/10.1073/pnas.0914054107

36. Wilson R, Cochrane D, Mihailidi, A, Small J. Mobile apps to support caregiver-resident communication in long-term care: systematic search and content analysis. JMIR Aging. 2020;3 (1):e17136. https://doi.org/10.2196/17136

37. Hampson C, Morris K. Dementia: sustaining self in the face of cognitive decline. Geriatrics. 2016;1(4):25. https://doi.org/10.3390/geriatrics1040025

38. England SE. Private troubles, master narratives: dilemmas of dementia care in a short story. Gerontologist. 2017;57(5):963-8. https://doi.org/10.1093/geront/gnw086

39. Williams KN, Herman R, Gajewski B, Wilson K. Elderspeak communication: Impact on dementia care. American Journal of Alzheimer's Disease \& Other Dementias ${ }^{\circledR}$. 2009;24(1):11-20. https:// doi.org/10.1177/1533317508318472

40. Kemper S, Ferrell P, Harden T, Finter-Urczyk A, Billington C. Use of elderspeak by young and older adults to impaired and unimpaired listeners. Aging, Neuropsychology, and Cognition. 1998;5(1):43-55.

https://doi.org/10.1076/anec.5.1.43.22

41. Williams K, Kemper S, Hummert, ML. Improving nursing home communication: an intervention to reduce elderspeak. The Gerontologist. 2003;43(2):242-7.

https://doi.org/10.1093/geront/43.2.242

42. van Weert JC, van Dulmen AM, Spreeuwenberg PM, Ribbe MW, Bensing JM. Effects of snoezelen, integrated in $24 \mathrm{~h}$ dementia care, on nurse-patient communication during morning care. Patient Education and Counseling. 2005;58(3):312-26. https://doi.org/10.1016/j.pec.2004.07.013

43. Gentry RA, Fisher JE. Facilitating conversation in elderly persons with Alzheimer's disease. Clinical Gerontologist. 2007; 31(2):77-98. https://doi.org/10.1300/J018v31n02_06

44. Lann-Wolcott H, Medvene LJ, Williams K. Measuring the person-centeredness of caregivers working with nursing home residents with dementia. Behavior Therapy. 2011;42(1):89-99. https://doi.org/10.1016/j.beth.2010.02.005

45. McConnell ES, Meyer J. Assessing Quality for People Living With Dementia in Residential Long-Term Care: Trends and Challenges. Gerontology and Geriatric Medicine. 2019;5:1-7. https://doi.org/10.1177/2333721419861198

46. Manthorpe J, Samsi K. Person-centered dementia care: current perspectives. Clinical Interventions in Aging. 2016;11:1733-40. https://doi.org/10.2147/CIA.S104618

47. Touhy TA. Dementia, personhood, and nursing: learning from a nursing situation. Nursing Science Quarterly. 2004;17(1):43-9. https://doi.org/10.1177/0894318403260639

48. Ashworth A, Ashworth P. The lifeworld as phenomenon and as research heuristic, exemplified by a study of the lifeworld of a person suffering Alzheimer's disease. Journal of Phenomenological Psychology. 2003;34(2):179-205.

49. Boumans J, van Boekel LC, Baan CA, Luijkx KG. How can autonomy be maintained and informal care improved for people with dementia living in residential care facilities: a systematic literature review. Gerontologist. 2019;59(6):e709-30. https://doi.org/10.1093/geront/gny096

50. Boersma P, van Weert JC, Lissenberg-Witte BI, van Meijel B, Dröes RM. Testing the implementation of the veder contact method: a theatre-based communication method in dementia care. The Gerontologist. 2019;59(4):780-91. 
https://doi.org/10.1093/geront/gnx200

51. Milte R, Shulver W, Killington M, Bradley C, Ratcliffe J, Crotty M. Quality in residential care from the perspective of people living with dementia: the importance of personhood. Archives of Gerontology and Geriatrics. 2016;63:9-17. https://doi.org/10.1016/j.archger.2015.11.007

52. Chenoweth L, Stein-Parbury J, Lapkin S, Wang A, Liu Z, Williams A. Effects of person-centered care at the organisational- level for people with dementia. a systematic review. PLoS One. 2019;14(2):e0212686. https://doi.org/10.1371/journal.pone.0212686

53. Gall D, Preßler J, Hurtienne J, Latoschik ME. Self-organizing knowledge management might improve the quality of personcentered dementia care: a qualitative study. International Journal of Medical Informatics. 2020;139:104132.

https://doi.org/10.1016/j.ijmedinf.2020.104132

54. Kim D, Sakong H, Yoon J. A delphi study for developing a person-centered dementia care online education program in longterm care facilities. Korean Academy of Community Health Nursing. 2019;30(3):295-306. https://doi.org/10.12799/jkachn.2019.30.3.295

55. Nowaskie D, Carvell CA, Alder CA, LaMantia MA, Gao S, Brown $S$, et al. Care coordinator assistants: job satisfaction and the importance of teamwork in delivering person-centered dementia care. Dementia. 2020;19(5):1560-72. https://doi.org/10.1177/1471301218802739

56. Tullo ES, Young TJ, Lee RP. Medical students' views about person-centered communication in dementia care. Dementia. 2018;17(5):573-84. https://doi.org/10.1177/1471301216651981

57. Kitwood T. The technical, the personal, and the framing of dementia. Social Behaviour. 1988;3(2):161-79.

58. Rogers CR. The foundations of a person-centered approach. In Rogers CR. editor. A way of being. New York: Houghton Miffin Company; 1995. p. 113-36.

59. Sakamoto ML, Moore SL, Johnson ST. "I'm still here": personhood and the early-onset dementia experience. Journal of Gerontological Nursing. 2017;43(5):12-7. https://doi.org/10.3928/00989134-20170309-01

60. Phutela D. The importance of non-verbal communication. IUP Journal of Soft Skills. 2015;9(4):43-9.

61. Wied TS, Poth A, Pantel J, Oswald F, Haberstroh J. How do dementia researchers view support tools for informed consent procedures of persons with dementia? Zeitschrift für Gerontologie und Geriatrie. 2020;54:667-75. https://doi.org/10.1007/s00391-020-01779-2

62. Kolanowski A, Van Haitsma K, Penrod J, Hill N, Yevchak A. "Wish we would have known that!" communication breakdown impedes person-centered care. The Gerontologist. 2015; 55(Suppl_1):S50-60. https://doi.org/10.1093/geront/gnv014
63. Bosco A, Schneider J, Coleston-Shields DM, Orrell M. Dementia care model: promoting personhood through co-production. Archive of Gerontology and Geriatrics. 2019;81:59-73. https://doi.org/10.1016/j.archger.2018.11.003

64. Chalmers JM. Behavior management and communication strategies for dental professionals when caring for patients with dementia. Special Care in Dentistry. 2000;20(4):147-54. https://doi.org/10.1111/j.1754-4505.2000.tb01152.x

65. Gladman J, Jones R, Radford K, Walker E, Rothera I. Personcentered dementia services are feasible, but can they be sustained? Age and ageing. 2007;36(2):171-6. https://doi.org/10.1093/ageing/afl161

66. Ripich DN, Ziol E, Fritsch T, Durand EJ. Training Alzheimer's disease caregivers for successful communication. Clinical Gerontologist. 2000;21(1):37-56.

https://doi.org/10.1300/J018v21n01_05

67. Williams CL, Parker C. Development of an observer rating scale for caregiver communication in persons with Alzheimer's disease. Issues in Mental Health Nursing. 2012;33(4):244-50. https://doi.org/10.3109/01612840.2011.653040

68. Athlin E, Norberg A. Interaction between the severely demented patient and his caregiver during feeding: a theoretical model. Scandinavian Journal of Caring Sciences. 1987;1(3-4): $117-23$

69. Hall K, Lind C, Young JA, Okell E, Van Steenbrugge W. Familiar communication partners' facilitation of topic management in conversations with individuals with dementia. International Journal of Language \& Communication Disorders. 2018;53(3):564-75. https://doi.org/10.1111/1460-6984.12369

70. McEvoy P, Bellass S. Using drawings as a reflective tool to enhance communication in dementia care. Nursing Standard. 2017;31(19):46-52. https://doi.org/10.7748/ns.2017.e10460

71. Söderlund M, Cronqvist A, Norberg A, Ternestedt BM, Hansebo $\mathrm{G}$. Conversations between persons with dementia disease living in nursing homes and nurses-qualitative evaluation of an intervention with the validation method. Scandinavian Journal of Caring Sciences. 2016;30(1):37-47. https://doi.org/10.1111/scs.12219

72. Gilmore-Bykovskyi AL, Roberts TJ, Bowers BJ, Brown RL. Caregiver person-centeredness and behavioral symptoms in nursing home residents with dementia: A Timed-Event Sequential Analysis. Gerontologist. 2015;55(Suppl 1):S61-6. https://doi.org/10.1093/geront/gnu164

73. Jablonski RA, Winstead V, Geldmacher DS. Description of process and content of online dementia coaching for family caregivers of persons with dementia. Healthcare. 2019;7(1):13. https://doi.org/10.3390/healthcare7010013

74. van der Ploeg ES, Eppingstall B, Camp CJ, Runci SJ, Taffe J, O'Connor DW. A randomized crossover trial to study the 
effect of personalized, one-to-one interaction using Montessori-based activities on agitation, affect, and engagement in nursing home residents with Dementia. International Psychogeriatrics. 2013;25(4):565-75.

https://doi.org/10.1017/S1041610212002128

75. Coleman CK, Medvene LJ. A person-centered care intervention for geriatric certified nursing assistants. The Gerontologist. 2013; 53(4):687-98. https://doi.org/10.1093/geront/gns135

76. Williams KN, Herman RE. Linking resident behavior to dementia care communication: effects of emotional tone. Behavior Therapy. 2011;42(1):42-6.

https://doi.org/10.1016/j.beth.2010.03.003 